\title{
MECHANISMS LINKING WORK AND FAMILY: CLARIFYING THE RELATIONSHIP BETWEEN WORK AND FAMILY CONSTRUCTS
}

\author{
JEFFREY R. EDWARDS \\ University of North Carolina \\ NANCY P. ROTHBARD \\ Northwestern University
}

\begin{abstract}
Work-family research emphasizes the importance of mechanisms that link work and family. However, these mechanisms typically are described in metaphoric terms poorly suited to rigorous research. In this article we translate work-family linking mechanisms into causal relationships between work and family constructs. For each relationship we explain its sign and causal structure and how it is influenced by personal intent. We show how these respecified linking mechanisms constitute theoretical building blocks for developing comprehensive models of the work-family interface.
\end{abstract}

In recent years the amount of research into the linkages between work and family has grown dramatically (Burke \& Greenglass, 1987; Eckenrode \& Gore, 1990; Zedeck, 1992). This research has been stimulated by fundamental changes in the substance and structure of work and family roles, such as the increasing prevalence of dualearner couples, the influx of women into the workforce, and family arrangements that deviate from traditional gender-based roles. This research has debunked the myth that work and family are independent (Blood \& Wolfe, 1960; Dubin, 1973), demonstrating instead that work and family are closely interconnected domains of human life (Burke \& Greenglass, 1987; Kanter, 1977; Voydanoff, 1987).

Linkages between work and family are important to organizations, families, and society. Many organizations are expanding operations globally (van Bergeijk \& Mensink, 1997) and, therefore, require key employees to travel or work abroad. These assignments can strain family relationships and compel employees to withdraw or resign (Shaffer \& Harrison, 1998), which, in turn, hinders global operations. Analogously, many families require income from both parents to cover expenses, and these dualearner families place pressure on organizations

We thank Jane E. Dutton, Kamela R. Edwards, and three anonymous reviewers for their helpful comments during the development of this article. to implement family-friendly policies (McShulskis, 1997). These policies help ease family demands and, by doing so, reduce employee absenteeism and turnover (Landauer, 1997). Thus, linkages between work and family affect organizational performance and family functioning, both of which are important markers of societal well-being (Diener \& Suh, 1997).

Work-family researchers have identified numerous mechanisms linking work and family (Burke \& Greenglass, 1987; Evans \& Bartolome, 1986; Lambert, 1990; Payton-Miyazaki \& Brayfield, 1976; Zedeck, 1992). Although their research has provided rich, detailed descriptions of the work-family interface, it has two major shortcomings. One is the sheer number of linking mechanisms described. Different terms have been used for fundamentally similar mechanisms (Staines, 1980; Zedeck, 1992), and common themes across mechanisms have been overlooked. This profusion of terminology implies distinctions among linking mechanisms that are not conceptually meaningful and inhibits the accumulation of knowledge regarding a core set of linking mechanisms.

Second, linking mechanisms are typically described with metaphoric language that provides no clear translation into propositions regarding the relationship between specific work and family constructs (Lambert, 1990; Rice, Near, \& Hunt, 1980). This translation is necessary to move beyond descriptive accounts of the work-family in- 
terface to rigorous research into causal relationships that link the work and family domains (Frone, Russell, \& Cooper, 1994; Kingston, 1989; Lambert, 1990; Near, Rice, \& Hunt, 1980; Rice et al., 1980).

Here, we review and critique linking mechanisms examined in work-family research, and we translate these mechanisms into causal relationships between specific work and family constructs. The article contains three major sections. In the first we review linking mechanisms discussed in the work-family literature, noting conceptual redundancies, clarifying important distinctions, and identifying common themes. In the second we explain how current conceptualizations of linking mechanisms fail to specify basic properties of relationships between work and family constructs, such as the sign and causal structure of these relationships. And in the third we translate linking mechanisms into theoretical statements framed as causal relationships between work and family constructs. This translation resolves ambiguities regarding the causal processes underlying work-family linking mechanisms and yields conceptual building blocks researchers may use to develop comprehensive theories of the work-family interface.

Before proceeding, we should clarify the theoretical contribution we intend to provide. We do not presume to develop a comprehensive theory of the work-family interface. Such an undertaking would exceed the scope of a journal article, given what is required to transform workfamily linking mechanisms from ambiguous metaphor to formal theory. Rather, our goal is more modest: we intend to respecify work-family linking mechanisms as causal relationships between work and family constructs. This goal befits the current status of theory regarding the work-family interface, which has yet to resolve basic conceptual issues concerning the meaning and causal structure of work-family linking mechanisms.

Our respecification of work-family linking mechanisms yields conceptual building blocks researchers may use to develop comprehensive theories of the work-family interface, as we later illustrate. Our objectives echo Whetten's (1989) observation that most theorists do not generate new theory from scratch but, rather, improve on what currently exists. In this spirit we provide a version of what Weick describes as emergent products [that] summarize progress, give direction, and serve as placemarkers. They have vestiges of theory but are not themselves theory. Then again, few things are full-fledged theories. The key lies in the context-what came before, what comes next? (1995: 389).

With regard to work-family linking mechanisms, we review and critique what has come before, and we provide a foundation for developing what we believe should come next.

\section{MECHANISMS LINKING WORK AND FAMILY}

As stated previously, numerous mechanisms linking work and family have been identified (Burke \& Greenglass, 1987; Evans \& Bartolome, 1984; Lambert, 1990; Payton-Miyazaki \& Brayfield, 1976; Zedeck, 1992). Here, we organize these mechanisms into six general categories: spillover, compensation, segmentation, resource drain, congruence, and work-family conflict. In this section we review and integrate these mechanisms by consolidating terms that describe fundamentally similar processes, drawing distinctions within and between each mechanism, and identifying points of similarity across mechanisms. This review provides the necessary foundation for our critique and respecification of linking mechanisms as causal relationships between work and family constructs.

To establish boundary conditions for this review, we first define the terms work, family, and linking mechanism. We define work as instrumental activity intended to provide goods and services to support life (Piotrkowski, Rapoport, \& Rapoport, 1987). Work typically entails membership in a market or employing organization that compensates the worker for his or her contributions (Burke \& Greenglass, 1987; Kabanoff, 1980). Work may provide intrinsic rewards (Deci \& Ryan, 1985), but its primary goal is to obtain extrinsic rewards (Locke \& Latham, 1990).

Family we define as persons related by biological ties, marriage, social custom, or adoption (Burke \& Greenglass, 1987; Piotrkowski et al., 1987). Like work, family signifies membership in a social organization to which the person contributes (Zedeck, 1992). However, these contributions are intended not to earn goods and services but, rather, to maintain the family and enhance its well-being. 
These definitions of work and family are intentionally broad, encompassing not only nuclear families in which one or both parents work but also working teenagers; single working adults with siblings, parents, or other relations; and other persons who work and have immediate or extended families.

We define a linking mechanism as a relationship between a work construct and a family construct. Linking mechanisms can exist only when work and family are conceptually distinct. Thus, we exclude situations in which work and family are too closely intertwined to be considered separately, a condition labeled identity or integration in the work-family literature (Burke \& Greenglass, 1987; Morf, 1989; Payton-Miyazaki \& Brayfield, 1976; Zedeck, 1992). This condition is exemplified by family-run businesses, in which family members are also supervisors, coworkers, or subordinates of one another (PaytonMiyazaki \& Brayfield, 1976). In addition, linking mechanisms entail relationships that span the work and family domains, as opposed to relationships among constructs within either domain (Lambert, 1990; Near et al., 1980). Finally, linking mechanisms may represent either causal or noncausal relationships (Morf, 1989). We later elaborate alternative causal structures underlying work-family linkages.

A final boundary condition concerns our focus on the individual level of analysis. Many researchers have examined linkages between individuals' work and family experiences and the psychological dynamics that influence these linkages (Burke \& Greenglass, 1987; Eckenrode \& Gore, 1990; Lambert, 1990; Zedeck, 1992). The volume and importance of this research justify our examination of work-family linkages at the individual level. We acknowledge the value of studying work-family linkages at other levels of analysis, such as dual-earner couples (Bielby \& Bielby, 1989), family systems (Cox \& Paley, 1997), work and family institutions (Dubin, 1973), and national cultures (Aryee, 1992; Keller, 1987).

\section{Spillover}

Spillover refers to effects of work and family on one another that generate similarities between the two domains (Burke \& Greenglass, 1987; Evans \& Bartolome, 1986; Lambert, 1990; Near et al., 1980; Staines, 1980; Zedeck, 1992). These similarities usually are described in terms of work and family affect (i.e., mood and satisfaction), values (i.e., the importance ascribed to work and family pursuits), skills, and overt behaviors. Other terms that capture the essence of spillover include generalization, isomorphism, continuation, extension, familiarity, and similarity (Staines, 1980; Zedeck, 1992).

Two versions of spillover have been discussed in the work-family literature. One characterizes spillover as similarity between a construct in the work domain and a distinct but related construct in the family domain (Judge \& Watanabe, 1994; Zedeck, 1992). This version of spillover is exemplified by the positive association between job and family satisfaction (Gutek, Repetti, \& Silver, 1988; Near et al., 1980; Piotrkowski et al., 1987) and between work and family values (Payton-Miyazaki \& Brayfield, 1976; Piotrkowski, 1979).

A second version describes spillover as experiences transferred intact between domains (Near, 1984; Near et al., 1980; Payton-Miyazaki \& Brayfield, 1976; Repetti, 1987), as when work fatigue is displayed at home (Eckenrode \& Gore, 1990). This version of spillover does not represent a linking mechanism, because, by itself, it does not entail a relationship between a work construct and a family construct. For instance, the display of work fatigue at home indicates that an experience generated in one domain is exhibited in another domain, but it does not indicate that a construct in the latter domain is affected. If such an effect occurs, as when work fatigue inhibits the fulfillment of family role demands (Eckenrode \& Gore, 1990; Greenhaus \& Beutell, 1985), then a link between a work construct and a family construct has been established.

\section{Compensation}

Compensation represents efforts to offset dissatisfaction in one domain by seeking satisfaction in another domain (Burke \& Greenglass, 1987; Champoux, 1978; Lambert, 1990; Zedeck, 1992). Other terms that capture the core meaning of compensation include contrast, complementarity, competition, regeneration, and heteromorphism (Staines, 1980: Zedeck, 1992).

Two forms of compensation have been distinguished in the work-family literature. First, a person may decrease involvement in the dissatisfying domain and increase involvement in a 
potentially satisfying domain (Champoux, 1978; Evans \& Bartolome, 1984; Lambert, 1990; Staines, 1980; Zedeck, 1992). Involvement itself has been defined as the perceived importance of a domain (Champoux, 1978; Lambert, 1990; Lobel, 1991), time spent in a domain (Lobel, 1991; Small \& Riley, 1990), and attention devoted to a domain (Kanter, 1977; Small \& Riley, 1990; Voydanoff, 1987). Hence, this form of compensation may be conceived as the reallocation of importance, time, or attention from a dissatisfying domain to a potentially satisfying domain.

Second, the person may respond to dissatisfaction in one domain by pursuing rewards in another (Champoux, 1978; Kando \& Summers, 1971; Zedeck, 1992). By "rewards," we mean experiences that may fulfill the person's desires and, by doing so, enhance his or her satisfaction (Porter \& Lawler, 1968). This form of compensation has been differentiated further into supplemental and reactive compensation (Kando \& Summer, 1971; Zedeck, 1992).

Supplemental compensation occurs when rewards that are insufficient in one domain are sought in the other domain (Evans \& Bartolome, 1986; Kando \& Summers, 1971; Zedeck, 1992). Here, the person seeks rewards in the latter domain that add to those in the former domain so that the cumulative rewards across domains are fulfilling (Kabanoff \& O'Brien, 1980; Staines, 1980). For example, a person with little autonomy at work may seek autonomy outside of work (Evans \& Bartolome, 1984; Kabanoff, 1980). Reactive compensation occurs when undesirable experiences in one domain are redressed by an individual's seeking contrasting experiences in the other domain (Kando \& Summers, 1971; Zedeck, 1992), such as resting at home after a tiring day at work or throwing oneself into work to avoid thinking about family problems (Evans \& Bartolome, 1986; Kando \& Summers, 1971; Zedeck, 1992).

Although both supplemental and reactive compensation involve the pursuit of rewards in an alternative domain, supplemental compensation is prompted by insufficient positive experiences, whereas reactive compensation arises from excess negative experiences. Both supplemental and reactive compensation are related to compensation that entails shifting involvement between domains, in that (1) in seeking rewards in another domain, the person may need to reallocate time and attention to that domain, and (2) shifting involvement from one domain to another will enhance overall satisfaction only if the latter domain provides valued rewards (Edwards, 1992; Rice, McFarlin, Hunt, \& Near, 1985).

\section{Segmentation}

Segmentation is the separation of work and family, such that the two domains do not affect one another (Burke \& Greenglass, 1987; Lambert, 1990; Zedeck, 1992). Segmentation originally was viewed as a natural division of work and family, owing to the separation of the two domains in time and space and to the inherently different functions they serve (Blood \& Wolfe, 1960; Dubin, 1973). However, this view of segmentation has been challenged by researchers who have demonstrated that work and family are closely related domains of human life (Burke \& Greenglass, 1987; Kanter, 1977; Voydanoff, 1987). Consequently, segmentation is now viewed as an active process whereby people maintain a boundary between work and family (Eckenrode \& Gore, 1990; Lambert, 1990; Morf, 1989; Near, 1984).

This process was described by Piotrkowski (1979), who found that people may actively suppress work-related thoughts, feelings, and behaviors while in the family domain, and vice versa. The active separation of work and family may be viewed as a method of coping with stress from either domain (Lambert, 1990; Piotrkowski, 1979; Rice et al., 1980) or as way of maintaining a preferred degree of connection between work and family (Kanter, 1977).

Other terms that capture the substance of segmentation include compartmentalization, independence, separateness, disengagement, neutrality, and detachment (Lambert, 1990; Pryor, 1987; Zedeck, 1992).

\section{Resource Drain}

Resource drain refers to the transfer of finite personal resources, such as time, attention, and energy, from one domain to another (Eckenrode \& Gore, 1990; Piotrkowski, 1979; Small \& Riley, 1990; Staines, 1980; Tenbrunsel, Brett, Maoz, Stroh, \& Reilly, 1995). Resource drain is analogous to those forms of compensation that entail a shift of time or attention between domains (Lobel, 1991; Small \& Riley, 1990). However, as 
noted previously, compensation is an active response to dissatisfaction in one domain (Burke \& Greenglass, 1987; Evans \& Bartolome, 1986; Lambert, 1990; Zedeck, 1992), whereas resource drain simply refers to the transfer of resources between domains, regardless of the impetus for the transfer. Moreover, unlike resource drain, compensation includes the shift between domains of variables other than personal resources, such as domain importance, and also may entail the pursuit of rewards in other domains.

\section{Congruence}

Congruence refers to similarity between work and family, owing to a third variable that acts as a common cause (Morf, 1989; Zedeck, 1992). These common causes include personality traits, genetic factors, general behavioral styles, and social and cultural forces (Frone et al., 1994; Morf, 1989; Staines, 1980; Zedeck, 1992). For example, dispositional affect (Watson \& Clark, 1984) may influence both work satisfaction and family satisfaction, thereby inducing a positive spurious relationship between these two variables (Frone et al., 1994). Congruence is analogous to spillover, in that both lead to similarities between work and family. However, spillover attributes these similarities to the effect of one domain on the other, whereas congruence attributes these similarities to a third variable that affects both domains.

\section{Work-Family Conflict}

Work-family conflict is a form of interrole conflict in which work and family role demands are mutually incompatible so that meeting demands in one domain makes it difficult to meet demands in the other (Burke \& Greenglass, 1987; Cooke \& Rousseau, 1984; Greenhaus \& Beutell, 1985). Role demands may originate from expectations expressed by work and family role senders, as well as from values held by the person regarding his or her own work and family role behavior (Kahn \& Quinn, 1970). Work-family conflict is aversive, because intrinsic and extrinsic rewards are often contingent upon meeting role demands (French, Caplan, \& Harrison, 1982), and when work and family demands are in conflict, obtaining rewards in one domain requires foregoing rewards in the other (Evans \& Bartolome,
1984; Zedeck, 1992). Work-family conflict also has been termed opposition and incompatibility (Burke \& Greenglass, 1987; Payton-Miyazaki \& Brayfield, 1976; Voydanoff, 1989).

Greenhaus and Beutell (1985) distinguish three forms of work-family conflict. Time-based conflict occurs when devoting time to the demands of one domain consumes time needed to meet demands of the other domain (Repetti, 1987; Staines, 1980). According to Greenhaus and Beutell, demands may go unmet when the person is either physically absent from a domain or is mentally preoccupied with another domain. Thus, time-based conflict incorporates resource drain as the transfer of time or attention between domains. However, time-based conflict adds the stipulation that the time or attention transferred from a domain leaves demands in that domain unmet.

Strain-based conflict occurs when strain (e.g., dissatisfaction, tension, anxiety, and fatigue) from one domain makes it difficult to meet demands of the other domain. Greenhaus and Beutell (1985) do not explicitly state why strain makes demands difficult to meet, but, presumably, strain reduces personal resources (e.g., energy and physical or mental capacity) needed for role performance (Pleck, Staines, \& Lang, 1980). Strain-based conflict does not connote conflicting demands per se but, rather, indicates that mere participation in a domain can produce strain that hampers role performance in another domain.

Finally, behavior-based conflict occurs when behaviors developed in one domain are incompatible with role demands in the other domain, and the person is unable to adjust behavior when moving between domains. For example, a confrontational approach to solving work problems may be applied inappropriately to family problems (Eckenrode \& Gore, 1990; Greenhaus \& Beutell, 1985; Pearlin \& Schooler, 1978). Behaviorbased conflict signifies a form of spillover in which behavior developed in one domain influences behavior in the other domain, with the added condition that the transferred behavior inhibits role performance in the latter domain. Note that behavior-based conflict need not entail conflicting demands. Rather, it merely requires that behavior developed in one domain interfere with role performance in another domain. 
PROBLEMS WITH CURRENT CONCEPTUALIZATIONS OF WORK-FAMILY LINKING MECHANISMS

The linking mechanisms reviewed above have undeniably enhanced our understanding of the work-family interface. However, attempts to translate these mechanisms into relationships between work and family constructs reveal several important ambiguities. Perhaps the most fundamental ambiguity concerns the sign of the relationship, meaning whether an increase in one construct is associated with an increase or decrease in the other construct.

In some cases the sign of the relationship implied by a linking mechanism is explicitly stated. For example, several investigators have asserted that spillover, compensation, and segmentation represent positive, negative, and null relationships, respectively (Judge \& Watanabe, 1994; Near, 1984; Staines, 1980; Tenbrunsel et al., 1995; Zedeck, 1992). However, in many cases the sign of the relationship is unstated or confounded with the benefit or harm resulting from the relationship (Tenbrunsel et al., 1995). For example, researchers often describe "positive" spillover as work satisfaction that enhances family functioning and "negative" spillover as work dissatisfaction that hinders family functioning (Eckenrode \& Gore, 1990; Evans \& Bartolome, 1984; Payton-Miyazaki \& Brayfield, 1976; Piotrkowski, 1979; Voydanoff, 1989). Although the terms positive and negative suggest a difference in sign, both of these forms of spillover represent a single statistically positive relationship between work satisfaction and family functioning.

A more concrete example is provided by Lambert, who presents path diagrams of relationships between work and family constructs and labels each path + or - , not to specify the sign of the relationship but, rather, to convey whether the relationship yields "positive or negative results" (1990: 248). This use of + and - labels likely will hinder the translation of Lambert's (1990) diagrams into causal models, which invariably use + and - to represent the statistical sign of a relationship, as opposed to the benefit or harm resulting from a relationship (James, Mulaik, \& Brett, 1982).

A second ambiguity concerns the causal structure of the relationship between work and family constructs (Frone et al., 1994; Lambert,
1990; Near, 1984; Near et al., 1980). With few exceptions, work-family linkages are specified as simple bivariate associations. This specification overlooks numerous alternative causal structures that may generate relationships between work and family constructs. For example, emotional spillover is often characterized as a positive correlation between job and family satisfaction (Gutek et al., 1988; Judge \& Watanabe, 1994; Rice et al., 1980; Staines, 1980). However, this correlation may be spurious, attributable to a common cause, such as dispositional affect, rather than a causal relationship between emotion in the two domains (Frone et al., 1994; Morf, 1989; Staines, 1980; Zedeck, 1992). Likewise, a negative correlation between work and family involvement interpreted as compensation (Champoux, 1978) may be spurious, arising from subscription to traditional gender roles that encourage greater work involvement for men and greater family involvement for women (Bielby \& Bielby, 1989; Gutek, Searle, \& Klepa, 1991; Voydanoff, 1988).

A null relationship between work and family constructs is typically equated with segmentation (Judge \& Watanabe, 1994) but may result from countervailing positive and negative effects representing simultaneous spillover and compensation, as when job dissatisfaction induces family dissatisfaction but also prompts the person to seek greater satisfaction with family (Champoux, 1978; Kabanoff, 1980; Tenbrunsel et al., 1995).

Conversely, work and family constructs may be correlated even when segmentation precludes a causal relationship between them, as when dispositional variables create spurious relationships between work and family constructs (Frone et al., 1994; Morf, 1989; Zedeck, 1992). As these examples illustrate, relationships between work and family constructs cannot be meaningfully conceptualized or interpreted unless their causal structures are clearly specified (Frone et al., 1994; Near, 1984; Near et al., 1980).

A third ambiguity entails the forces that give rise to relationships between work and family constructs. These forces include the intent of the person; the behavior of others in the person's work and family environments; and policies and practices attributable to organizations, governments, and society. Given our emphasis on the psychological dynamics of work-family linkages, we focus on intent, meaning whether a 
work-family linkage is purposely created, modified, or eliminated by the person (Judge \& Watanabe, 1994; Near, 1984; Near, Rice, \& Hunt, 1987; Rice et al., 1980). Whereas sign and causal structure describe how work and family constructs are related, intent provides an explanation as to why they are related.

Intent is perhaps most explicit in discussions of compensation, which is invariably described as deliberate efforts by the person to create contrasting work and family experiences (Burke \& Greenglass, 1987; Evans \& Bartolome, 1984; Kabanoff, 1980; Lambert, 1990; Zedeck, 1992). However, studies typically view a negative correlation between work and family constructs as sufficient evidence for compensation (Champoux, 1978; Judge \& Watanabe, 1994; Kabanoff \& O'Brien, 1980). As Near et al. (1987) emphasize, a negative relationship between work and family constructs may arise for many reasons, only one of which is personal intent.

Unlike compensation, spillover and segmentation have not been consistently described as intentional or unintentional. For example, spillover has been characterized as the deliberate application of skills learned in one domain to the other domain (Crouter, 1984a; Repetti, 1987) and as the inadvertent transfer of mood between domains (Lambert, 1990; Near, 1984; Williams \& Alliger, 1994). Likewise, segmentation has been described as active attempts to separate work and family (Eckenrode \& Gore, 1990; Piotrkowski, 1979) and as an inherent boundary between the two domains (Blood \& Wolfe, 1960; Dubin, 1973).

Work-family conflict has been attributed to both person and situation forces (Greenhaus \& Beutell, 1985), although it is unclear whether these forces signify personal intent. For example, time-based conflict may arise from changes in work schedules beyond the control of the person or from conscious time allocation decisions made by the person. In short, the issue of intent is fundamental to the origin, meaning, and implications of work-family linkages, but this issue has been largely overlooked in the workfơmily literature.

In summary, current conceptualizations of linking mechanisms exhibit important ambiguities regarding the sign, causal structure, and intent of relationships between work and family constructs. These ambiguities inhibit the translation of linking mechanisms into precise theoretical statements and make it difficult to deter- mine whether empirical findings support $\alpha$ particular linking mechanism. Ambiguities such as these prompted Rice et al. to consign spillover and compensation to the status of "pretheoretical metaphors, sometimes useful in general discourse, but little else" (1980: 61). However, abandoning linking mechanisms entirely would effectively discard decades of research and may generate considerable resistance from workfamily researchers. As an alternative, we attempt to resolve these ambiguities by respecifying work-family linking mechanisms as causal relationships between work and family constructs.

\section{RESPECIFYING WORK-FAMILY LINKING MECHANISMS AS CAUSAL RELATIONSHIPS BETWEEN WORK AND FAMILY CONSTRUCTS}

In this section we recast work-family linking mechanisms as causal relationships between work and family constructs. For each linking mechanism we identify relevant work and family constructs, explain the sign and causal structure of the relationship between these constructs, and discuss under what conditions the relationship is intentional. For the sake of simplicity, the figures we use to depict these relationship show causal flows from work to family, although these figures can be adapted readily to show causal flows from family to work, as we later illustrate.

A central goal of this section is to explain not only how work-family linking mechanisms occur but also why they occur. To this end, we draw from basic principles of role theory (Kahn, Wolf, Quinn, Snoek, \& Rosenthal, 1964; Katz \& Kahn, 1978); specifically, we assume that both work and family entail multiple roles, each of which places demands on the person. Meeting these demands enhances role performance, which, in turn, brings extrinsic rewards from others (e.g., pay, advancement, and approval from work and family role members) and intrinsic rewards from the self (e.g., a sense of accomplishment and fulfillment of goals and values pertaining to work and family).

Intrinsic and extrinsic rewards bring positive moods (e.g., satisfaction, joy, and pride), whereas lack of rewards produces negative moods (e.g., dissatisfaction, sadness, and disappointment). Negative moods stimulate coping efforts intended to change aspects of the work and 
family domains (e.g., renegotiate role demands and acquire resources needed to meet demands), adapt to conditions in the domains (e.g., devalue or ignore disappointing aspects of work or family), or avoid a domain in part or whole (e.g., spend less time at work or with family). The goal of coping is to enhance well-being associated with work and family and, by doing so, increase overall well-being. Although these principles are anchored in role theory, they are common to theories of how people interact with situations and how these interactions influence affect and behavior (e.g., Edwards, 1992; French et al., 1982; Locke, 1976; Rice et al., 1985).

\section{Spillover}

Recall that spillover refers to the effects of work and family on one another that make the two domains similar. Similarity connotes a positive relationship between $\alpha$ work construct and a family construct (Judge \& Watanabe, 1994; Tenbrunsel et al., 1995; Zedeck, 1992), regardless of whether this relationship benefits or harms the person (cf. Lambert, 1990). The causal structure and intent of this relationship vary according to the work and family constructs involved. Here we examine mood, values, skills, and behavior, given the prevalence of these constructs in spillover research (Burke \& Greenglass, 1987; Eckenrode \& Gore, 1990; Lambert, 1990; Near, 1984; Near et al., 1980; Staines, 1980; Voydanoff, 1989; Zedeck, 1992).

Mood. Mood spillover occurs when mood in one domain affects mood in the other domain. This effect may be explained in terms of a causal sequence that links mood in one domain to performance and rewards in the other. Specifically, positive moods enhance cognitive functioning, increase task activity and persistence, and promote positive interactions with others, each of which facilitates role performance (Staw, Sutton, \& Pelled, 1994). Role performance brings intrinsic and extrinsic rewards, which, in turn, enhance mood.

By the same argument, negative moods from one domain inhibit role performance and rewards in the other domain, producing negative moods in that domain. For example, Barling and Macewen (1992) found that negative moods originating from work interfered with family relationships and family role performance, which, in turn, were linked to dissatisfaction with family.
Similarly, Nolen-Hoeksema, Parker, and Larson (1994) found that negative moods were associated with pessimism and rumination, which may cause people to neglect demands in the other domain.

The effects of mood in one domain on role performance, rewards, and mood in the other domain are depicted in Figure $1 A$, paths $\alpha, d$, and e. ${ }^{1}$ Figure $1 \mathrm{~A}$ also shows that domainspecific mood (i.e., mood originating in a particular domain) influences general mood (path b; Rice et al., 1985), which may also affect performance, rewards, and mood in the other domain (paths $c, d$, and e).

Mood spillover is largely unintentional, because it operates through cognitive and motivational processes that do not require intent. For instance, negative moods inhibit problem solving and reduce self-efficacy (Staw et al., 1994), and people need not try to make these effects occur. However, mood spillover is more likely intentional when it refers to expressed (i.e., overtly displayed) rather than felt (i.e., internal) moods. Work and family roles carry expectations regarding mood expression (Ashforth \& Humphrey, 1993; Rafaeli \& Sutton, 1987), and these expectations prompt people to selectively display appropriate moods. For instance, anger and irritation from family problems may be intentionally concealed by service workers (Asshforth \& Humphrey, 1993) but deliberately displayed by bill collectors (Sutton, 1991). Thus, intent regulates the degree to which felt mood is manifested as expressed mood, and people regulate expressed moods to fulfill role expectations, enhance role performance, and receive role rewards.

Values. The spillover of values between work and family suggests two causal structures. First, work and family are socializing forces that affect values regarding life as a whole, and these life values influence values specific to a domain (Kanter, 1977; Payton-Miyazaki \& Brayfield, 1976; Piotrkowski, 1979; Repetti, 1987). This process signifies an indirect relationship between work and family values, mediated by general life values (Figure lB, paths b and c). Second, values in one domain may directly affect values in the

\footnotetext{
${ }^{1}$ Note that family mood refers to how the person feels about his or her family-not the mood of members of the person's family.
} 


\section{Causal Structures for Spillover Between Work and Family}

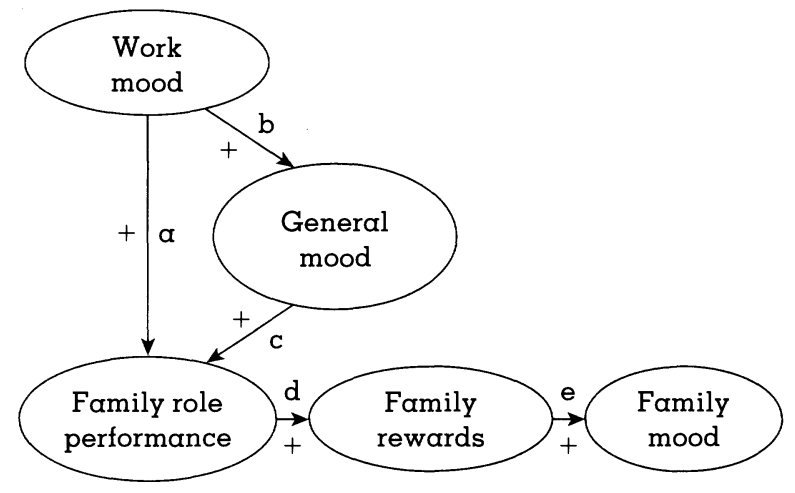

(A) Spillover of work mood to family mood

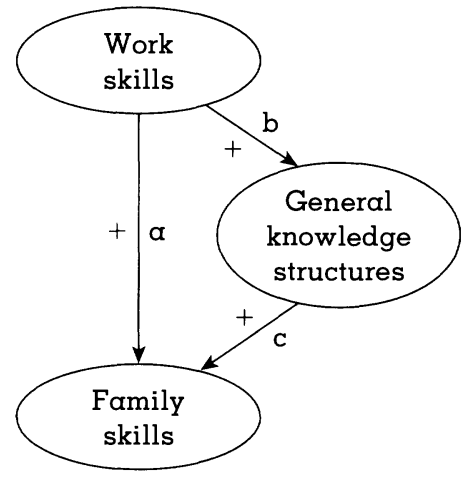

(C) Spillover of work skills to family skills

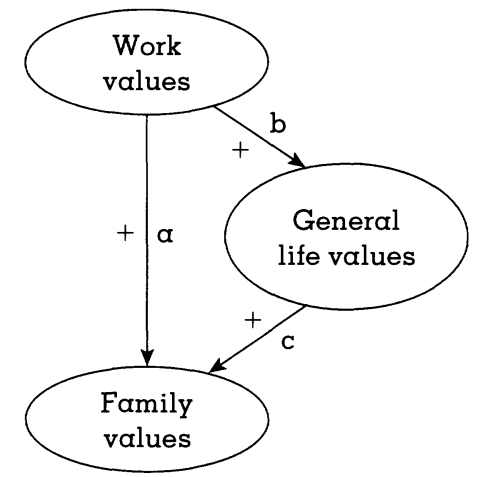

(B) Spillover of work values to family values

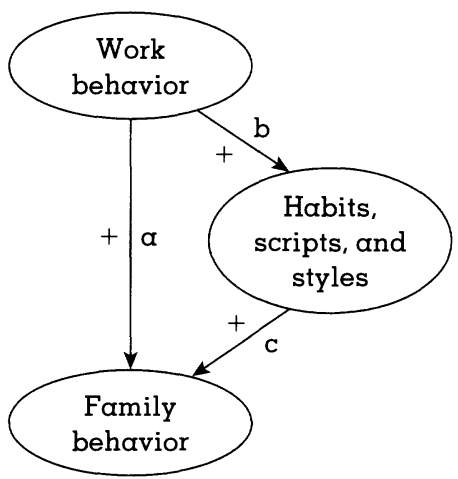

(D) Spillover of work behavior to family behavior

Note: For simplicity, these figures depict spillover from work to family. Each figure may be reversed to depict spillover from family to work. Also, Figure lA refers to positive mood (e.g., satisfaction, pleasure, joy), rather than negative mood (e.g., dissatisfaction, distress, anger).

other domain (Figure 1B, path $\alpha$ ). For example, people in jobs where obedience is valued over self-direction tend to emphasize obedience over self-direction in their children (Kohn, 1963; Payton-Miyazaki \& Brayfield, 1976; Pearlin \& Kohn, 1966). For either causal structure, the relationship between work and family values may arise from the unintentional transmission of ingrained value structures between domains (Lord \& Maher, 1991) or from intentional strivings for value consistency between work and family, particularly for people who desire a consistent self-concept (Cialdini, Trost, \& Newsom, 1995).

Skills. The spillover of work and family skills implies two causal pathways. First, skills obtained in one domain may be abstracted into general knowledge structures, or schema (Lord
\& Kernan, 1987; Lord \& Maher, 1991) that apply across life domains (Figure 1C, paths b and c). For example, problem-solving skills developed at work may enhance one's analytical reasoning capabilities, which may, in turn, facilitate solving family problems, even when specific aspects of problems in the two domains differ.

Second, skills obtained in one domain may be directly exported to the other domain (Figure 1C, path a; Repetti, 1987). For instance, Crouter (1984a) found that employees applied participative management skills acquired at work to family situations. This transfer of specific skills between domains does not entail the development of general schema but, instead, implies a direct transport of skills from one domain to another. Research on learning transfer (Guberman \& 
Greenfield, 1991) suggests that the skill transfer between work and family is more likely when skills are abstracted into general knowledge structures, because this abstraction enables skill transfer, despite differences in specific problems in the two domains. Consequently, the indirect effect in Figure $1 C$ (paths $b$ and $c$ ) is more likely than the direct effect (path a). Both indirect and direct skill transfer are typically intentional, assuming people deliberately muster skills to meet role expectations and enhance role performance. However, unintentional transfer may occur when skills become embedded in schema that are firmly ingrained and require little conscious information processing (Lord \& Maher, 1991).

Behavior. Behavioral spillover may follow a causal structure similar to that for values and skills. For instance, behaviors developed in one domain may become ingrained as habits or scripts that influence behaviors across domains (Figure 1D, paths b and c; Champoux, 1978; Greenhaus \& Beutell, 1985; Lord \& Kernan, 1987; Staines, 1980; Zedeck, 1992). Alternately, behaviors in one domain may directly influence behaviors in the other domain without becoming generalized as habits or scripts (Figure lD, path a). For example, studies show that teachers develop interaction patterns with students that directly shape their behavior as parents (Ispa, Gray, \& Thornburg, 1984).

The direct transfer of behavior between work and family is likely when situational cues (e.g., work and family role requirements) in the two domains are similar (Mischel, 1977). These two effects combine additively, such that the transfer of behaviors between domains is most likely when behaviors have been internalized as habits or scripts and situational cues in the domains are similar (Pervin, 1989; Schneider, 1983). We posit that behavioral spillover is unintentional for behaviors that are habitual or scripted (Ashforth \& Fried, 1988; Lord \& Kernan, 1987) or when situational cues in work and family are similar and strong (Mischel, 1977). In contrast, behavioral spillover is intentional for behaviors the person deems applicable to role expectations in both domains (Crouter, 1984a,b).

\section{Compensation}

As discussed previously, compensation occurs when dissatisfaction in one domain prompts a person to increase involvement or seek rewards in the other. Compensation refers to a decrease in involvement or rewards in the dissatisfying domain, coupled with an increase in these constructs in the other domain. Therefore, the relationship between these constructs across domains is negative (Staines, 1980; Tenbrunsel et al., 1995; Zedeck, 1992). Moreover, compensation is intentional, for it represents active attempts to reallocate involvement or seek alternative rewards (Burke \& Greenglass, 1987; Champoux, 1978; Lambert, 1990; Zedeck, 1992). However, compensation implies different causal structures, depending on whether it refers to the relationship between work and family involvement or rewards.

Recall that involvement may be viewed as time, attention, or importance associated with a domain. The relationship linking these constructs across domains is direct. For instance, in response to declining work satisfaction, a person may devote less time to work and more to family (Figure 2A, path b; Staines, 1980; Zedeck, 1992). ${ }^{2}$ This relationship is imperfect, because time may be allocated to and from domains other than work or family, such as personal or community activities. The relationship between work and family attention is also direct, since the person may shift attention from a dissatisfying domain directly to a potentially satisfying domain (Figure 2B, path b; Edwards, 1992; Evans \& Bartolome, 1986; Lambert, 1990). Finally, the relationship between work and family importance is direct (Figure 2C, path b), because a person who assigns less importance to a dissatisfying domain may seek satisfaction by ascribing greater importance to other potentially satisfying domains (Lobel, 1991).

Like time, the relationships between work and family attention and importance are imperfect, given that attention and importance may be distributed among domains other than work and

\footnotetext{
${ }^{2}$ Some researchers may prefer to conceptualize compensation as a response to increased dissatisfaction, as opposed to decreased satisfaction. To accommodate this alternative conceptualization, one can modify the causal structures in Figure 2 by (1) replacing satisfaction with dissatisfaction and (2) reversing the signs leading to and from satisfaction so that the arrows from satisfaction in Figures $2 A, 2 B$, and $2 C$ are negative and the arrows to and from satisfaction in Figure 2D are negative and positive, respectively. These modified causal structures will be conceptually equivalent to those shown in Figure 2.
} 


\section{FIGURE 2}

\section{Causal Structures for Compensation Between Work and Family}

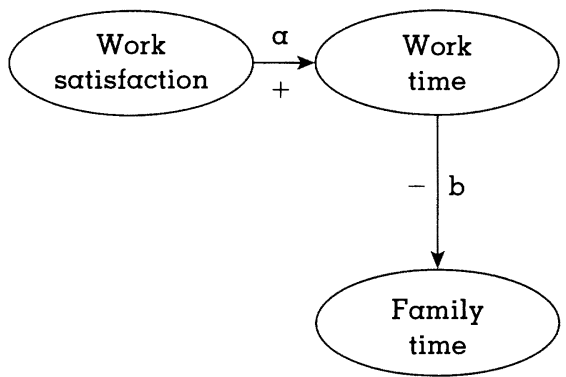

(A) Compensation for work and family time

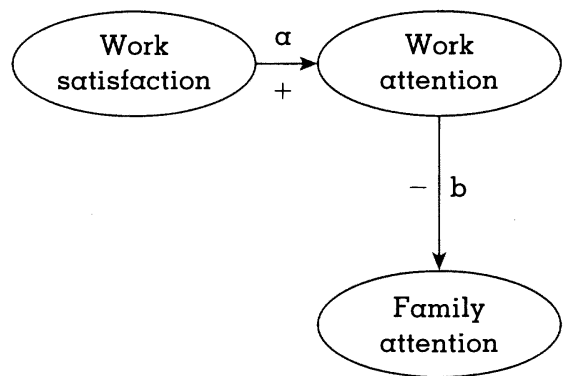

(B) Compensation for work and family attention

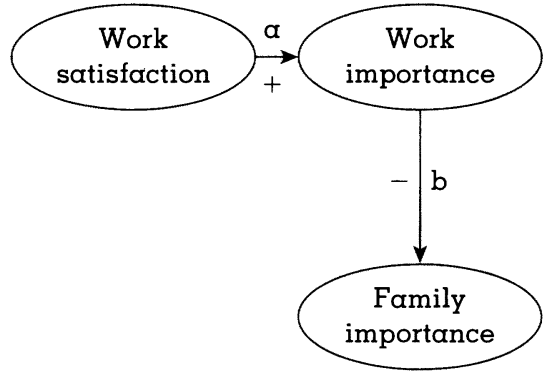

(C) Compensation for work and family importance

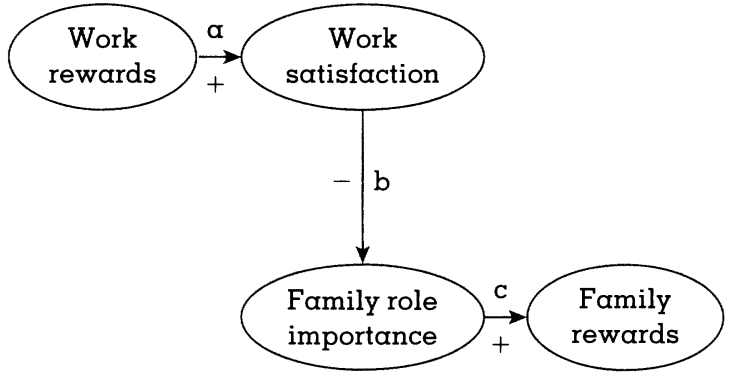

(D) Compensation for work and family rewards

Note: For simplicity, these figures depict compensation as shifting involvement from work to family or as reduced work rewards that prompt the pursuit of family rewards. Each figure may be reversed to depict compensation as shifting involvement from family to work or as reduced family rewards that prompt the pursuit of work rewards.

family. Shifting time, attention, and importance to another domain may increase satisfaction for two reasons. First, time and attention are resources for meeting role expectations and therefore may enhance role performance and bring rewards, contributing to satisfaction. Second, time, attention, and importance intensify the effects of rewards on satisfaction, because focusing time and attention on a reward heightens satisfaction with that reward (Edwards, 1992; Greenhaus \& Beutell, 1985), and important rewards elicit greater satisfaction than unimportant rewards (Rice et al., 1985).

Figure 2D shows a hypothesized causal structure for compensation as seeking rewards in another domain. This structure indicates that decreased work rewards lead to decreased work satisfaction, which then leads to family role performance intended to yield desired family rewards. These rewards may be intrinsic to role performance itself (e.g., when work provides lit- the social contact, a person may perform family roles to obtain contact with family members) or extrinsic (e.g., insufficient recognition at work may prompt the person to perform family roles to earn recognition from family members). Although the relationship between work and family rewards is mediated by work satisfaction and family role performance, the link between domains (i.e., path $b$ ) is not mediated by a general life construct and, therefore, is a direct effect.

This causal structure applies to both supplemental and reactive compensation. As stated earlier, supplemental compensation occurs when insufficient rewards in one domain decrease satisfaction in that domain and invoke the pursuit of rewards in the other domain $-\alpha$ process that corresponds directly to Figure 2D. In contrast, reactive compensation occurs when excess undesirable experiences in a domain decrease satisfaction in that domain and lead to 


\section{Causal Structures for Segmentation Between Work and Family}

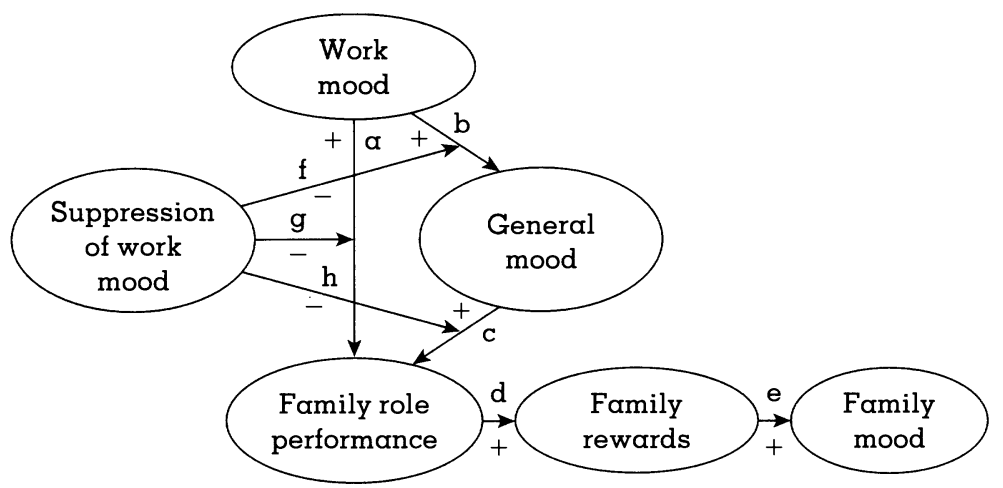

(A) Segmentation as the suppression of the effects of work mood on family functioning

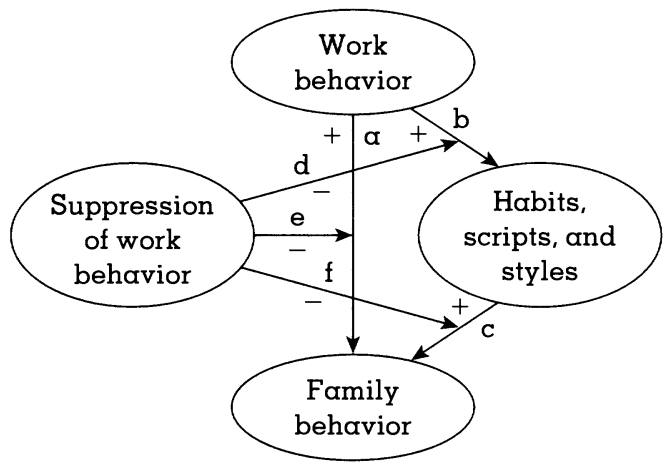

(B) Segmentation as the suppression of the effects of work behavior on family behavior

Note: For simplicity, these figures depict segmentation that dampens the effects of work on family. Each figure may be reversed to depict segmentation that dampens the effects of family to work. Also, Figure $3 \mathrm{~A}$ refers to positive mood (e.g., satisfaction, pleasure, joy), rather than negative mood (e.g., dissatisfaction, distress, anger).

the pursuit of contrasting pleasurable experiences in the other domain. Although these two forms of compensation differ on the surface, undesirable experiences that prompt reactive compensation typically can be reframed as the lack of pleasurable or rewarding experiences (e.g., excess noise implies insufficient quiet and excess fatigue implies insufficient rest). Thus, the causal structure in Figure 2D applies to reactive compensation, if undesirable experiences are reconstrued as insufficient rewards.

\section{Segmentation}

Segmentation refers to the active separation of work and family so that the two domains do not influence one another. Segmentation produces a null relationship between work and family constructs (Staines, 1980; Zedeck, 1992). However, a null relationship alone does not necessarily signify segmentation, because positive and negative effects between work and family constructs may combine to yield a null relationship (Champoux, 1978; Kabanoff, 1980; Tenbrunsel et al., 1995). Rather, segmentation requires that all direct and indirect effects between work and family constructs are null, thereby indicating a true lack of causal linkages between domains. Segmentation is also intentional, for it represents deliberate efforts to inhibit unwanted interference between domains (Lambert, 1990; Piotrkowski, 1979; Rice et al., 1980) or to maintain a preferred degree of connection between domains (Kanter, 1977).

Regarding causal structure, segmentation represents attempts to reduce the relationship 
between work and family constructs and, therefore, connotes a moderating or buffering effect. For example, the suppression of negative work moods while at home (Piotrkowski, 1979) may dampen the direct effect of an individual's work mood on family role performance (Figure $3 A$, path g). Analogously, the indirect effect of work mood on family role performance may be buffered by reducing the impact of work mood on general mood (Figure 3A, path $f$ ), suppressing negative general moods while at home (Figure $3 \mathrm{~A}$, path h), or both. Note that total removal of the effects of work mood on family role performance requires the complete buffering of path $\alpha$ and either path $b$ or $c$ in Figure 3A.

Figure 3B depicts a similar causal structure for behavioral segmentation, which may entail eliminating situational cues that invoke direct behavioral transfer (path e), preventing work behaviors from developing into habits (path d), or subduing habits originating from work while at home (path f). This logic can be used to derive causal structures for segmentation regarding other work-family linkages. Thus, segmentation represents intentional moderating effects that nullify relationships between work constructs and family constructs.

\section{Resource Drain}

Resources such as time, attention, and energy are finite, ${ }^{3}$ and those expended in one domain are unavailable for other domains (Eckenrode \& Gore, 1990; Piotrkowski, 1979; Small \& Riley, 1990; Staines, 1980). This constraint yields a negative direct relationship between work and family resources, such that resources devoted to one domain reduce resources available for the other domain (Figures 4A, 4B, and 4C; Piotrkowski, 1979; Repetti, 1987; Small \& Riley, 1990; Staines, 1980). This relationship is imperfect, since resources may be shifted among domains other than work and family, such as community and personal activities. For example, in response to increased time demands at work, a person may spend less time sleeping or pursuing hobbies, leaving family time intact.

\footnotetext{
${ }^{3}$ Although the pool of energy available to a person is finite in the short run, it may expand or contract in the long run because of aging, illness, changes in health habits (e.g., exercise and diet), and so forth.
}

FIGURE 4

Causal Structures for Resource Drain Between Work and Family

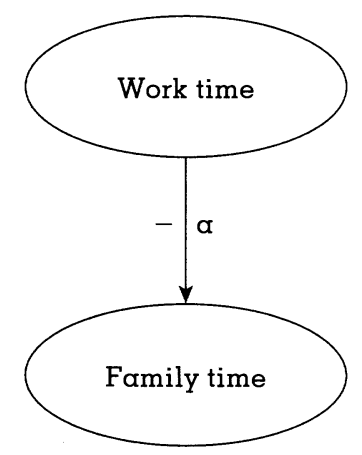

(A) Resource drain for work and family time

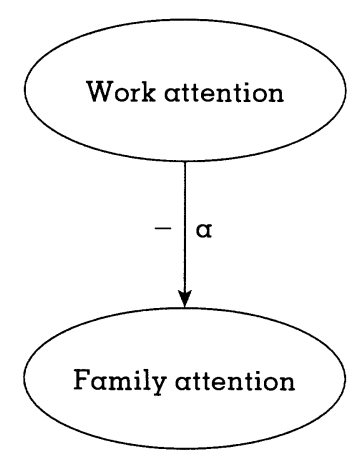

(B) Resource drain for work and family attention

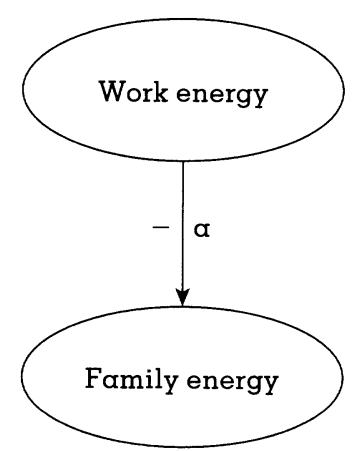

(C) Resource drain for work and family energy

Note: For simplicity, these figures depict resource drain from work to family. For each figure the causal flow may be reversed to depict resource drain from family to work.

In general, we view the negative relationship between work and family resources as intentional, arising from resource allocation decisions made by the person. However, unintentional relationships may also occur, as when 


\section{Causal Structures for Congruence Between Work and Family}

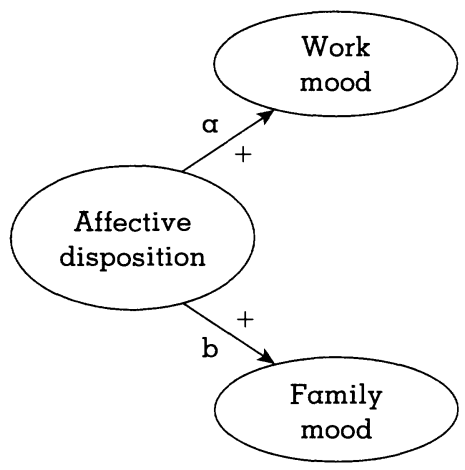

(A) Congruence of work and family mood

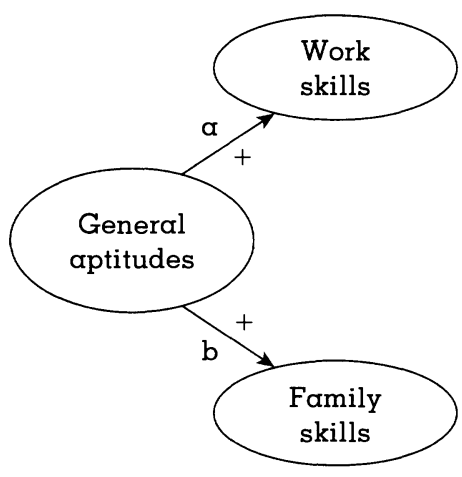

(C) Congruence of work and fomily skills

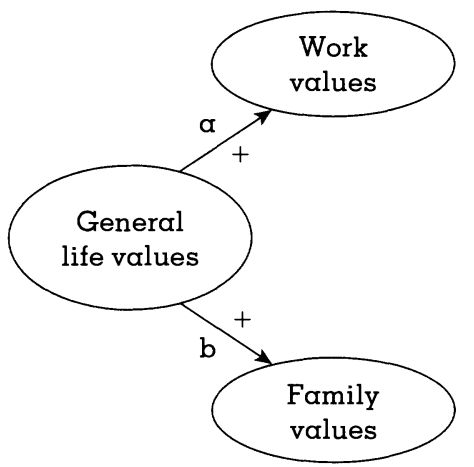

(B) Congruence of work and family values

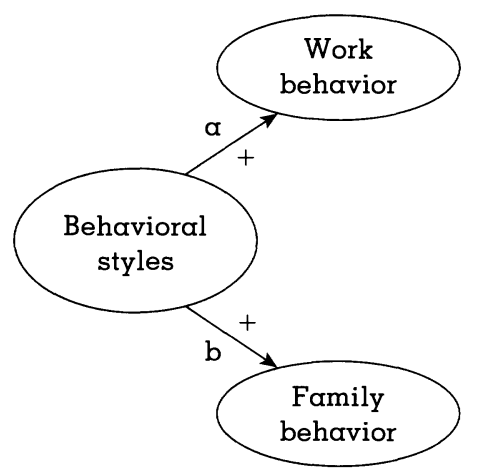

(D) Congruence of work and family behavior evening shift work makes it physically impossible to spend time with children during their normal waking hours (Burke \& McKeen, 1993; Shamir, 1983), or when the intrusion of family problems prevents an individual from focusing attention on work responsibilities (Cooke \& Rousseau, 1984; Crouter, 1984b; Voydanoff, 1988).

\section{Congruence}

Congruence indicates that work and family constructs are similar, owing to $\alpha$ common cause (Frone et al., 1994; Morf, 1989; Staines, 1980; Zedeck, 1992), thereby signifying a positive spurious relationship. This relationship may apply to a variety of constructs, such as those linked through spillover. For example, a relationship between work and family mood may arise from dispositional affect (Figure 5A; Frone et al., 1994;
Watson \& Clark, 1984). Likewise, overarching life values may create similarity between values pertaining to work and family (Figure 5B; Schwartz \& Bilsky, 1987). Analogously, general aptitudes and intelligence may contribute to skills specific to work and family (Figure 5C; Lubinski \& Dawis, 1990; Staines, 1980). Finally, similarity of behaviors exhibited in work and family domains (Greenhaus \& Beutell, 1985; Staines, 1980) may arise from general behavioral styles (Figure 5D; Ispa et al., 1984; Murphy, 1996).

We suggest that these relationships are primarily unintentional, because the general constructs shown in Figure 5 induce similarity between work and family constructs without conscious effort by the person. However, intentional relationships may occur, as when people strive for consistency in values or behaviors 
FIGURE 6

Causal Structures for Work-Family Conflict

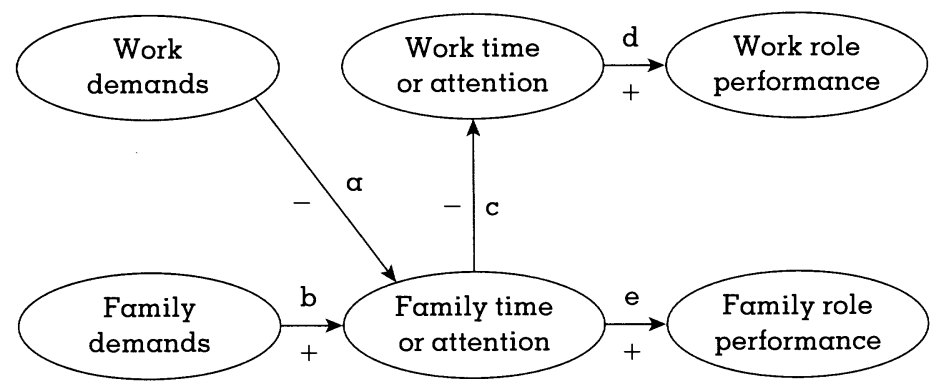

(A) Time-based conflict from work to family

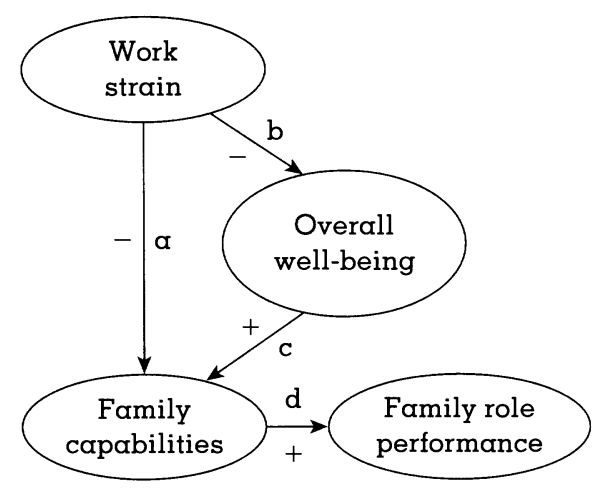

(B) Strain-based conflict from work to family

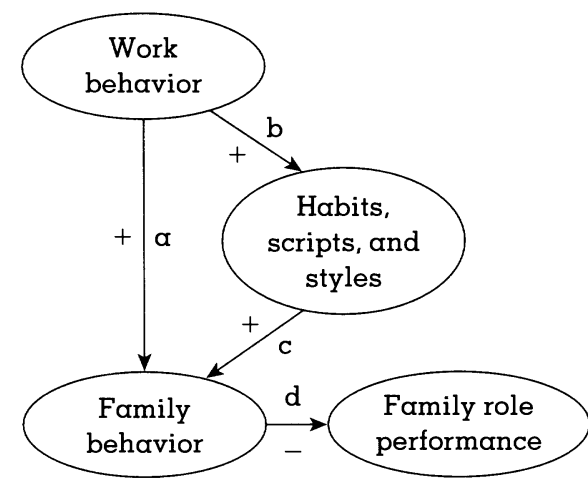

(C) Behavior-based conflict from work to family

Note: For simplicity, these figures depict conflict in which work interferes with family.

Each figure may be reversed to depict conflict in which family interferes with work.

across life domains (Cialdini et al., 1995; Mischel \& Peake, 1983), or they purposely apply general skills to specific work and family problems (Pearlin \& Schooler, 1978).

\section{Work-Family Conflict}

The three forms of work-family conflict identified by Greenhaus and Beutell (1985) imply different relationships between work and family constructs. As argued previously, time-based conflict is a form of resource drain, in which time or attention transferred from a domain hinders role performance in that domain but facilitates role performance in the receiving domain. This process is illustrated in Figure $6 \mathrm{~A}$, which shows that a decrease in family time or attention would reduce family role performance (path e) and increase work time or attention (path c), thereby increasing work role performance (path d). Figure $6 \mathrm{~A}$ also shows that work demands compete with family demands for family time or attention, as indicated by the negative and positive signs on paths $a$ and $b$, respectively. As with resource drain, the shift of time or attention between domains results from intentional allocation decisions.

Strain-based conflict suggests that increased strain in one domain reduces personal capabilities needed to meet demands in the other domain, thereby inhibiting role performance (Figure $6 \mathrm{~B}$ ). The impact of strain in one domain on capabilities in the other domain may be direct (Figure 6B, path $\alpha$ ) or indirect, mediated by overall well-being (e.g., life satisfaction and mental and physical health; Figure 6B, paths b and c). Available evidence suggests that this relationship is unintentional. For example, work may produce fatigue, tension, and frustration that interfere with family role performance (Greenhaus \& Beutell, 1985), without intentional efforts to create this interference. 
TABLE 1

Sign, Causal Structure, and Intent of Work-Family Linking Mechanisms

Sign

Causal structure

$-\quad$ Si

Intentional relationships

Direct effect

Spurious association

\begin{tabular}{|l|l|l|}
\hline $\begin{array}{l}\text { Compensation } \\
\text { Resource drain } \\
\text { Time-based conflict }\end{array}$ & Segmentation & Spillover \\
\hline & Segmentation & Spillover \\
\hline & & Congruence \\
\hline
\end{tabular}

Unintentional relationships

Direct effect

Indirect effect

\begin{tabular}{|l|l|l|}
\hline $\begin{array}{l}\text { Resource drain } \\
\text { Time-based conflict } \\
\text { Strain-based conflict }\end{array}$ & $\begin{array}{l}\text { Spillover } \\
\text { Behavior-based conflict }\end{array}$ \\
\hline Strain-based conflict & & $\begin{array}{l}\text { Spillover } \\
\text { Behavior-based conflict }\end{array}$ \\
\hline & & Congruence \\
\hline
\end{tabular}

Finally, behavior-based conflict represents a form of behavioral spillover (Figure 6C, path a or paths $b$ and $c$ ) in which behavior transferred from one domain inhibits role performance in another domain (Figure 6C, path d). This relationship is presumably unintentional, because the transferred behavior interferes with role performance and, therefore, reduces rewards received by the person (Greenhaus \& Beutell, 1985).

\section{IMPLICATIONS FOR RESEARCH ON WORK- FAMILY LINKING MECHANISMS}

Our specification of sign, causal structure, and intent regarding work-family linking mechanisms is summarized in Table l. This specification provides theoretical precision lacking in previous discussions of work-family linking mechanisms-a deficiency that scholars have lamented repeatedly in the work-family literature (Burke \& Greenglass, 1987; Kabanoff, 1980; Kingston, 1989; Lambert, 1990; Near et al., 1980,
1987; Rice et al., 1980; Voydanoff, 1989; Zedeck, 1992).

This specification also has several important implications for work-family research. First, the location of each linking mechanism within Table 1 constitutes a set of theoretical conditions that may be examined empirically-for example, compensation is specified as a negative, direct, intentional relationship between work and family constructs. All three of these conditions should be empirically verified before concluding that compensation has occurred. In contrast, in previous studies scholars have inferred compensation solely from a negative correlation between work and family constructs (Bolger, DeLongis, Kessler, \& Wethington, 1989; Champoux, 1978; Kabanoff \& O'Brien, 1980), thereby overlooking the crucial issues of causal structure and intent (Judge \& Watanabe, 1994; Near et al., 1987).

Second, linking mechanisms within a single cell constitute alternative explanations for observed relationships between work and family 
constructs. For instance, a positive, direct, unintentional relationship between work behavior and family behavior may be interpreted as either behavioral spillover or behavior-based conflict. Distinguishing between these two interpretations requires further reasoning and empirical evidence. Specifically, unlike behavioral spillover, behavior-based conflict indicates that behavior transferred from one domain inhibits role performance in another domain (Figure 6C, path d). By testing this additional relationship, researchers can determine whether evidence for behavioral spillover warrants interpretation as behavior-based conflict. Likewise, a negative, direct, intentional relationship between work time and family time suggests either resource drain or time-based conflict. Choosing between these interpretations requires additional measures of work and family demands and role performance and testing the full set of relationships depicted in Figure 6A.

Third, linking mechanisms in different cells may be integrated to derive more complete representations of the work-family interface. For example, spillover as a positive, direct, unintentional effect may be combined with compensation as a negative, direct, intentional effect, and this combined model could depict situations where work dissatisfaction simultaneously causes family dissatisfaction and prompts a person to seek satisfaction in the family domain (Champoux, 1978; Kabanoff, 1980; Tenbrunsel et al., 1995). Although these combined effects may yield a null relationship between work and family satisfaction, their causal structures would differentiate this relationship from segmentation, which entails the absence of direct or indirect effects between work and family constructs. Mechanisms in other cells may be added to develop more complete models of the work-family interface, as we later illustrate.

Finally, empty cells signal opportunities for investigating relationships between work and family constructs not captured by current linking mechanisms. For instance, no linking mechanism specifies a negative spurious relationship between work and family constructs. However, such a relationship may arise between work and family involvement, as when subscription to traditional gender roles leads men to become more involved in work than in family and women to become more involved in family than in work (Bielby \& Bielby, 1989; Gutek et al., 1991; Voydanoff, 1988). Likewise, current
FIGURE 7

Illustrative Model of the Work-Family Interface

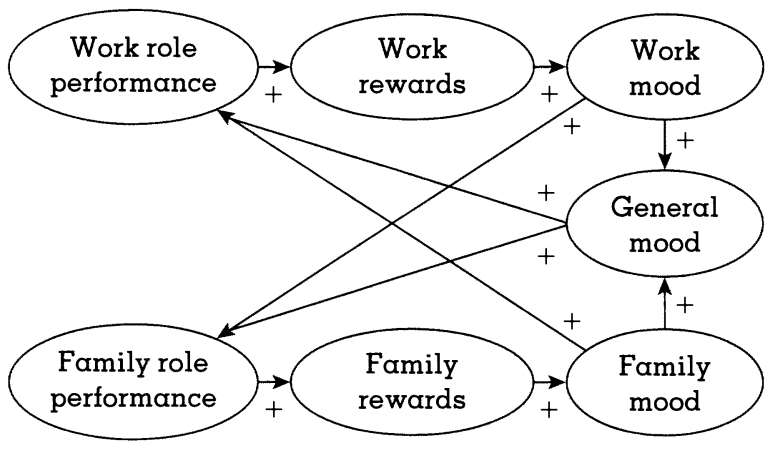

(A) Reciprocal spillover between work and family

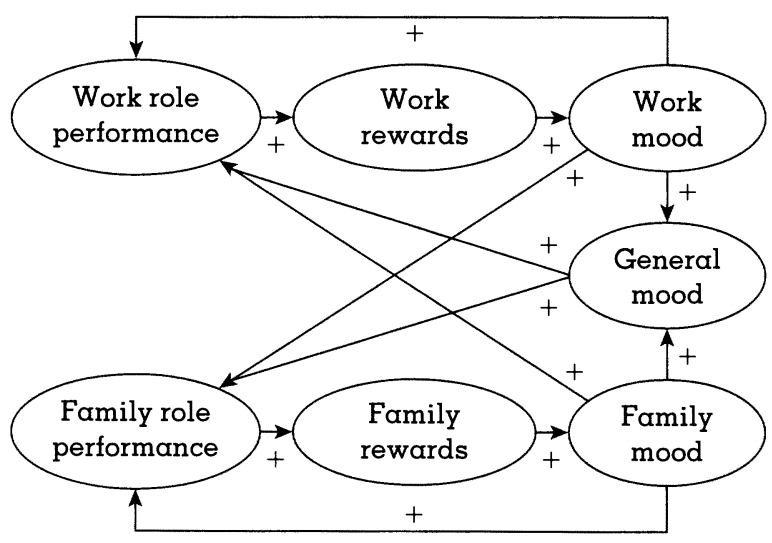

(B) Adding within-domain effects of mood on role performance

Note: Figures 7A through 7D refer to positive mood (e.g., satisfaction, pleasure, joy), rather than negative mood (e.g., dissatisfaction, distress, anger).

views of segmentation emphasize the active separation of work and family (Eckenrode \& Gore, 1990; Lambert, 1990; Morf, 1989; Near, 1984). However, work and family constructs may be unrelated for reasons other than personal intent. For example, work role demands often fluctuate irrespective of family role demands, and vice versa, leading to periods during which demands from both domains cannot be fulfilled (Greenhaus \& Beutell, 1985; Kahn et al., 1964). This situation represents a null relationship between work and family role demands that arises not from personal intent but from forces beyond the person's control. Other empty cells may be used to develop and test relationships between work and family constructs not yet considered in the work-family literature. 


\section{Continued}

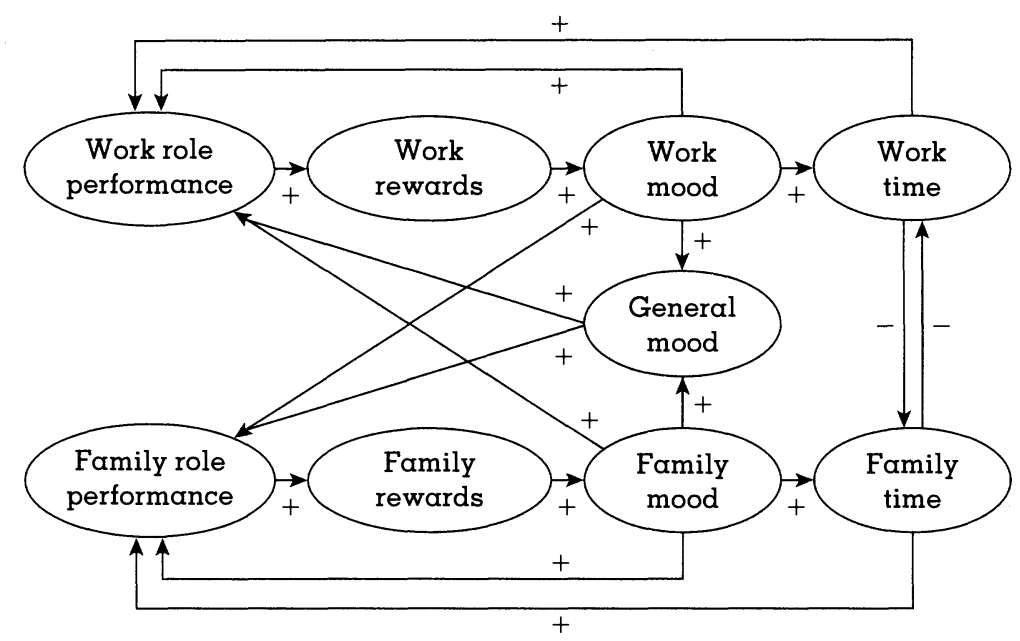

(C) Adding work and family time

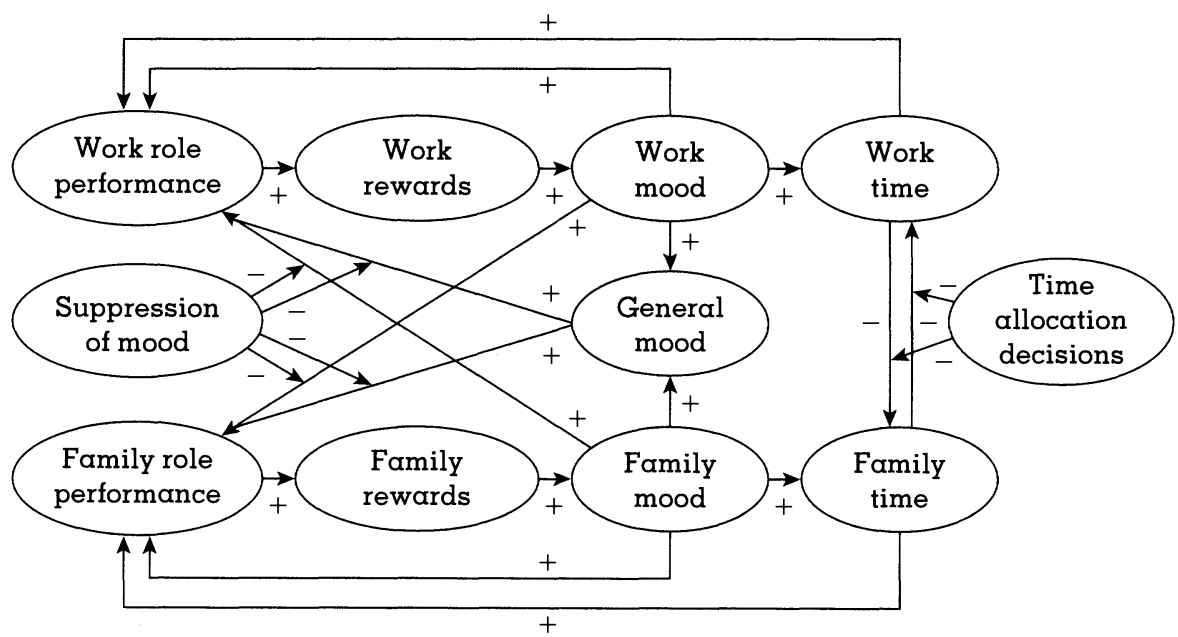

(D) Adding intentional time allocation decisions and segmentation as the suppression of mood effects on work and family role performance

Table 1 captures most of the work-family linking mechanisms studied to date and suggests new categories of relationships between work and family constructs. However, one may elaborate upon Table 1 to generate further possibilities. First, the classification of sign as positive, negative, and null may be extended to include nonlinear relationships. For example, mood spillover may be more pronounced for negative moods than for positive moods, implying a curvilinear relationship between work and family mood. Second, causal structure may be expanded to include indirect effects with multiple stages of mediation, or spurious associations owing to several common causes. Third, forces other than intent that influence work-family linkages may be considered, such as family structure, workplace policies, and societal and cultural norms. Thus, Table 1 provides a useful point of departure for developing more elaborate views of relationships between work and family constructs.

\section{AREAS FOR FURTHER THEORETICAL DEVELOPMENT}

Our central goal in this article has been to translate work-family linking mechanisms from their current metaphoric state into causal rela- 
tionships between work and family constructs. This translation provides theoretical building blocks that may be used to develop comprehensive theories of the work-family interface. To illustrate how these building blocks may be used, we draw from our specification of mood spillover in Figure $1 \mathrm{~A}$. We first extend this model to capture mood spillover not only from work to family but also from family to work, which yields Figure 7A.

This extended model provides two insights not evident from Figure 1A. First, mood spillover may operate through reciprocal relationships, in which work mood influences family role performance, which, in turn, affects family mood, work role performance, and work mood. These reciprocal effects may lead to upward or downward spirals in work and family mood over time. Second, general mood may influence role performance for both work and family. These effects follow a causal structure similar to mood congruence (Figure 5A) but show that general mood may influence domain-specific mood-not directly, but by affecting role performance and rewards.

Next, we elaborate the model in Figure $7 \mathrm{~A}$ by adding the effects of domain-specific mood on domain role performance, based on the reasoning that domain mood can influence role performance not only in other domains but also in the same domain (Staw et al., 1994). The resulting model (Figure 7B) captures relationships between mood and role performance that not only span domains but also occur within a domain.

To this model we add compensation by adding the reallocation of time between domains (Figure $2 \AA$ ), depicting time reallocations in both directions, and specifying mood as the impetus for these reallocations. We further incorporate the notion that time devoted to a domain may enhance role performance in that domain (Figure $6 \AA$ ). The resulting model (Figure $7 \mathrm{C}$ ) shows that mood affects role performance not only directly but also indirectly, through time allocation. For instance, a person experiencing negative work mood may perform family roles less effectively but, at the same time, may reallocate time from work to family, which would facilitate family role performance.

Finally, we add two moderator variablesone that depicts intentional time allocation decisions that dampen the tradeoff between work and family time and another that incorporates segmentation as the suppression of work and family mood (Figure 3A). This model (Figure 7D) emphasizes that personal intent moderates relationships that link work and family constructs, thereby casting the person as an active agent in managing the work-family interface.

We do not claim that the model in Figure 7D is comprehensive or superior to other possible models. Rather, we use it to illustrate how our respecified work-family linking mechanisms serve as building blocks to develop theories of the work-family interface. These building blocks may also be woven into existing theories in work-family research. For example, Frone, Yardley, and Markel (1997) present a model of the work-family interface that includes work and family time, behavior, and satisfaction, but they do not link these constructs across domains. These linkages may be developed by drawing from our respecified work-family linking mechanisms. Other models of the work-family interface may be enhanced similarly.

In addition to developing more complete models of the work-family interface, we believe another agenda for further theoretical development is to specify conditions under which different linking mechanisms will occur. In this article we explained why each individual linking mechanism occurs, and we noted that linking mechanisms may operate simultaneously. The next logical step is to explain when and why certain linking mechanisms occur and others do not. For example, under what conditions will the effects of compensation shown in Figure 7D swamp the effects of spillover so that the overall relationship between work and family mood is negative, rather than positive? Under what conditions will efforts to suppress mood fail, so that mood spillover overwhelms segmentation? Such questions can be investigated by identifying person and situation factors that promote certain linking mechanisms and inhibit others-a task that awaits future research.

A final area for further theoretical development is to relax the boundary conditions we have specified in this article. For instance, by emphasizing the psychological dynamics of work and family, we have devoted little attention to social, organizational, and cultural factors that may influence work-family linkages. For example, for dualearner couples, personal decisions to reallocate investment between work and family must take into account these same decisions made by one's spouse (Bielby \& Bielby, 1989). Similarly, linkages 
between work and family may be affected not only by variables in these two domains but also by variables in the broader cultural context that surrounds work and family (Aryee, 1992; Keller, 1987).

Moreover, work-family linkages may operate differently for different types of work and for different family structures. For instance, workfamily segmentation is perhaps easier when work involves extensive travel but is more difficult for fomily-run businesses. Likewise, workfamily conflict may be manageable for a married working parent with a supportive extended family but overwhelming for a single working parent with no extended family. Thus, differences in work and family arrangements should be considered when developing comprehensive models of the work-family interface.

\section{CONCLUSION}

We have reviewed and critiqued linking mechanisms examined in work-family research and respecified these mechanisms as relationships between work and family constructs. For each relationship we have explained its sign and causal structure and whether the relationship arises from intentional actions by the person. The properties of sign, causal structure, and intent provide $\alpha$ theoretical framework for examining relationships between work and family constructs- $a$ framework that incorporates linking mechanisms examined in previous workfamily research and reveals mechanisms yet to be considered. Relationships between work and family constructs embedded in this framework constitute theoretical building blocks that may be used to develop comprehensive theories of the work-family interface and to embellish existing theories in the work-family literature.

\section{REFERENCES}

Aryee, S. 1992. Antecedents and outcomes of work-family conflict among married professional women: Evidence from Singapore. Human Relations, 45: 813-837.

Ashforth, B. E., \& Fried, Y. 1988. The mindlessness of organizational behaviors. Human Relations, 41: 305-329.

Ashforth, B. E., \& Humphrey, R. H. 1993. Emotional labor in service roles: The influence of identity. Academy of Management Review, 18: 88-115.

Barling, J., \& Macewen, K. E. 1992. Linking work experiences to facets of marital functioning. Journal of Organizational Behavior, 13: 573-583.
Bielby, W. T., \& Bielby, D. D. 1989. Family ties: Balancing commitments to work and family in dual earner households. American Sociological Review, 54: 776-789.

Blood, R. O., \& Wolfe, D. M. 1960. Husbands and wives. New York: Macmillan.

Bolger, N., DeLongis, A., Kessler, R. C., \& Wethington, E. 1989. The contagion of stress across multiple roles. Journal of Marriage and the Family, 51: 175-183.

Burke, R. J., \& Greenglass, E. 1987. Work and family. In C. L. Cooper \& I. T. Robertson (Eds.), International review of industrial and organizational psychology: 273-320. New York: Wiley.

Burke, R. J., \& McKeen, C. A. 1993. Career priority patterns among managerial and professional women. Applied Psychology: An International Review, 42: 34l-352.

Champoux, J. E. 1978. Perceptions of work and nonwork: $\AA$ reexamination of the compensatory and spillover models. Sociology of Work and Occupations, 5: 402-422.

Cialdini, R. B., Trost, M. R., \& Newsom, J. T. 1995. Preference for consistency: The development of a valid measure and the discovery of surprising behavioral implications. Journal of Personality and Social Psychology, 69: 318-328.

Cooke, R. A., \& Rousseau, D. M. 1984. Stress and strain from family roles and work role expectations. Journal of $A p$ plied Psychology, 69: 252-260.

Cox, M. J., \& Paley, B. 1997. Families as systems. Annual Review of Psychology, 48: 243-267.

Crouter, A. C. 1984a. Participative work as an influence on human development. Journal of Applied Developmental Psychology, 5: 71-90.

Crouter, A. C. 1984b. Spillover from family to work: The neglected side of the work-family interface. Human Relations, 37: 425-441.

Deci, E. L., \& Ryan, R. M. 1985. Intrinsic motivation and selfdetermination in human behavior. New York: Plenum.

Diener, E., \& Suh, E. 1997. Measuring quality of life: Economic, social, and subjective indicators. Social Indicators Research, 40: 189-216.

Dubin, R. 1973. Work and non-work: Institutional perspectives. In M. D. Dunnette (Ed.), Work and non-work in the year 2001: 53-68. Monterey, CA: Brooks/Cole.

Eckenrode, J., \& Gore, S. 1990. Stress and coping at the boundary of work and family. In J. Eckenrode \& S. Gore (Eds.), Stress between work and family: 1-16. New York: Plenum.

Edwards, J. R. 1992. A cybernetic theory of stress, coping, and well-being in organizations. Academy of Management Review, 17: 238-274.

Evans, P., \& Bartolome, F. 1984. The changing pictures of the relationship between career and family. Journal of Occupational Behavior, 5: 9-21.

Evans, P., \& Bartolome, F. 1986. The dynamics of work-family relationships in managerial lives. International Review of Applied Psychology, 35(Special Issue): 371-395.

French, J. R. P., Jr., Caplan, R. D., \& Harrison, R. V. 1982. The mechanisms of job stress and strain. London: Wiley. 
Frone, M. R., Russell, M., \& Cooper, M. L. 1994. Relationship between job and family satisfaction: Causal or noncausal covariation? Journal of Management, 20: 565-579.

Frone, M. R., Yardley, J. K., \& Markel, K. S. 1997. Developing and testing an integrative model of the work-family interface. Journal of Vocational Behavior, 50: 145-167.

Greenhaus, J. H., \& Beutell, N. J. 1985. Sources of conflict between work and family roles. Academy of Management Review, 10: 76-88.

Guberman, S. R., \& Greenfield, P. M. 1991. Learning and transfer in everyday cognition. Cognitive Development, 6: 233-260.

Gutek, B. A., Repetti, R., \& Silver, D. 1988. Nonwork roles and stress at work. In C. L. Cooper \& R. Payne (Eds.), Causes, coping, and consequences of stress at work: 141-174. New York: Wiley.

Gutek, B. A., Searle, S., \& Klepa, L. 1991. Rational versus gender role explanations for work-family conflict. Journal of Applied Psychology, 76: 560-568.

Ispa, J. M., Gray, M. M., \& Thornburg, K. R. 1984. Childrearing attitudes of parents in person-oriented and thingoriented occupations: A comparison. Journal of Psychology, 117: 245-250.

James, L. R., Mulaik, S. A., \& Brett, J. M. 1982. Causal analysis: Assumptions, models and data. Beverly Hills, CA: Sage.

Judge, T. A., \& Watanabe, S. 1994. Individual differences in the nature of the relationship between job and life satisfaction. Journal of Occupational and Organizational Psychology, 67: 101-107.

Kabanoff, B. 1980. Work and nonwork: A review of models, methods, and findings. Psychological Bulletin, 88: 60-77.

Kabanoff, B., \& O'Brien, G. E. 1980. Work and leisure: A task attributes analysis. Journal of Applied Psychology, 65: 596-609.

Kahn, R. L., \& Quinn, R. P. 1970. Role stress: A framework for analysis. In A. McLean (Ed.), Occupational mental health: 50-115. New York: Rand McNally.

Kahn, R. L., Wolfe, D. M., Quinn, R. P., Snoek, J. D., \& Rosenthal, R. A. 1964. Organizational stress: Studies in role conflict and ambiguity. New York: Wiley.

Kando, T. M., \& Summers, W. C. 1971. The impact of work on leisure: Toward a paradigm and research strategy. Pacific Sociological Review, 14: 310-327.

Kanter, R. M. 1977. Work and family in the United States: $A$ critical review and agenda for research and policy. New York: Russell Sage Foundation.

Katz, D., \& Kahn, R. L. 1978. The social psychology of organizations (2nd ed.). New York: Wiley.

Keller, R. T. 1987. Cross-cultural influences on work and nonwork contributors to quality of life. Group and Organization Studies, 12: 304-318.

Kingston, P. W. 1989. Studying the work-family connection: Atheoretical progress, ideological bias, and shaky foundations for policy. Journal of Social Behavior and Personality, 3: 55-60.

Kohn, M. L. 1963. Social class and parent-child relationships:

\section{0.}

Lambert, S. J. 1990. Processes linking work and family: $A$ critical review and research agenda. Human Relations, 43: 239-257.

Landauer, J. 1997. Bottom-line benefits of work/life programs. HR Focus, 74(7): 3-4.

Lobel, S. A. 1991. Allocation of investment in work and family roles: Alternative theories and implications for research. Academy of Management Review, 16: 507-521.

Locke, E. A. 1976. The nature and causes of job satisfaction. In M. Dunnette (Ed.), Handbook of industrial and organizational psychology: 1297-1350. Chicago: Rand McNally.

Locke, E. A., \& Latham, G. P. 1990. A theory of goal setting and task performance. Englewood Cliffs, NJ: Prentice-Hall.

Lord, R. G., \& Kernan, M. C. 1987. Scripts as determinants of purposeful behavior in organizations. Academy of Management Review, 12: 265-277.

Lord, R. G., \& Maher, K. J. 1991. Cognitive theory in industrial and organizational psychology. In M. D. Dunnette \& L. M. Hough (Eds.), Handbook of industrial and organizational psychology (2nd ed.), vol. 2: 1-62. Palo Alto, CA: Consulting Psychologists Press.

Lubinski, D., \& Dawis, R. V. 1990. Aptitudes, skills, and proficiencies. In M. D. Dunnette \& L. M. Hough (Eds.), Handbook of industrial and organizational psychology (2nd ed.), vol. 3: 1-60. Palo Alto, CA: Consulting Psychologists Press.

McShulskis, E. 1997. Work and family benefits are increasingly popular. HRMagazine, 42(7): 26-29.

Mischel, W. 1977. The interaction of person and situation. In D. Magnusson \& N. S. Endler (Eds.), Personality at the crossroads: Current issues in interactional psychology: 333-352. New York: Lawrence Erlbaum Associates.

Mischel, W., \& Peake, P. K. 1983. Analyzing the construction of consistency in personality. In M. M. Page (Ed.), Personality: Current theory and research: 233-262. Lincoln: University of Nebraska Press.

Morf, M. 1989. The work/life dichotomy. Westport, CT: Quorum.

Murphy, K. R. 1996. Individual differences and behavior in organizations: Much more than g. In K. Murphy (Ed.), Individual differences and behavior in organizations: 3-30. San Francisco: Jossey-Bass.

Near, J. P. 1984. Predictive and explanatory models of work and nonwork. In M. D. Lee \& R. N. Kanungo (Eds.), Management of work and personal life: Problems and opportunities: 67-85. New York: Praeger.

Near, J., Rice, R., \& Hunt, R. 1980. The relationship between work and nonwork domains: A review of empirical research. Academy of Management Review, 5: 415-429.

Near, J. P., Rice, R. W., \& Hunt, R. G. 1987. Job satisfaction and life satisfaction: A profile analysis. Social Indicators Research, 19: 383-401.

Nolen-Hoeksema, S., Parker, L. E., \& Larson, J. 1994. Ruminative coping with depressed mood following loss. Journal of Personality and Social Psychology, 67: 92-104. 
Payton-Miyazaki, M., \& Brayfield, A. H. 1976. The good job and the good life: Relationship of characteristics of employment to general well-being. In A. D. Biderman \& T. F. Drury (Eds.), Measuring work quality for social reporting: 105-150. New York: Sage.

Pearlin, L., \& Kohn, M. 1966. Social class, occupational, and parental values: A cross-national study. American Sociological Review, 31: 466-479.

Pearlin, L. I., \& Schooler, C. 1978. The structure of coping. Journal of Health and Social Behavior, 19: 2-21.

Pervin, L. A. 1989. Persons, situations, interactions: The history of a controversy and a discussion of theoretical models. Academy of Management Review, 14: 350-360.

Piotrkowski, C. S. 1979. Work and the family system. New York: Free Press.

Piotrkowski, C. S., Rapoport, R. N., \& Rapoport, R. 1987. Families and work. In M. Sussman \& S. Steinmetz (Eds.), Handbook of marriage and the family: 251-283. New York: Plenum.

Pleck, J. H., Staines, G. L., \& Lang, L. 1980. Conflicts between work and family life. Monthly Labor Review, 103: 29-32.

Porter, L. W., \& Lawler, E. E. 1968. Managerial attitudes and performance. Homewood, IL: Dorsey Press.

Pryor, R. G. L. 1987. Differences among differences: In search of general work preference dimensions. Journal of Applied Psychology, 72: 426-433.

Rafaeli, A., \& Sutton, R. I. 1987. Expression of emotion as part of the work role. Academy of Management Review, 12: 23-37.

Repetti, R. L. 1987. Linkages between work and family roles. Applied Social Psychology Annual, 7: 98-127.

Rice, R. W., McFarlin, D. B., Hunt, R. G., \& Near, J. P. 1985. Organizational work and the perceived quality of life: Toward a conceptual model. Academy of Management Review, 10: 296-310.

Rice, R. W., Near, J. P., \& Hunt, R. G. 1980. The job-satisfaction/ life-satisfaction relationship: A review of empirical research. Basic and Applied Social Psychology, 1: 37-64.

Schneider, B. 1983. Interactional psychology and organizational behavior. In B. M. Staw \& L. L. Cummings (Eds.), Research in organizational behavior, vol. 5: 1-3l. Greenwich, CT: JAI Press.

Schwartz, S. H., \& Bilsky, W. 1987. Toward a universal psychological structure of human values. Journal of Personality and Social Psychology, 53: 550-562.

Shaffer, M. A., \& Harrison, D. A. 1998. Expatriates' psychological

Jeffrey R. Edwards is professor of management at the Kenan-Flagler Business School at the University of North Carolina. He received his Ph.D. in organizational psychology and theory from Carnegie Mellon University. His research interests include coping and well-being in organizations, person-environment fit, stress, work and family issues, and research methods.

Nancy P. Rothbard is a visiting assistant professor and postdoctoral fellow at Kellogg Graduate School of Management, Northwestern University. She received her Ph.D. in organizational behavior and human resource management at the University of Michigan. Her research interests include work motivation and engagement, identity, emotion, and work-life issues. 